\title{
Coiling of Large and Giant Aneurysms: Complications and Long-Term Results of 334 Cases
}

\author{
N. Chalouhi, S. Tjoumakaris, L.F. Gonzalez, A.S. Dumont, R.M. Starke, D. Hasan, C. Wu, S. Singhal, L.A. Moukarzel,
}

R. Rosenwasser, and P. Jabbour

\begin{abstract}
BACKGROUND AND PURPOSE: Large and giant intracranial aneurysms are increasingly treated with endovascular techniques. The goal of this study was to retrospectively analyze the complications and long-term results of coiling in large and giant aneurysms ( $\geq 10 \mathrm{~mm}$ ) and identify predictors of outcome.
\end{abstract}

MATERIALS AND METHODS: A total of 334 large or giant aneurysms ( $\geq 10 \mathrm{~mm}$ ) were coiled in our institution between 2004 and 2011. Medical charts and imaging studies were reviewed to determine baseline characteristics, procedural complications, and clinical/ angiographic outcomes. Aneurysm size was $15 \mathrm{~mm}$ on average. Two hundred twenty-five aneurysms were treated with conventional coiling; 88, with stent-assisted coiling; 14, with parent vessel occlusion; and 7, with balloon-assisted coiling.

RESULTS: Complications occurred in $10.5 \%$ of patients, with 1 death $(0.3 \%)$. Aneurysm location and ruptured aneurysms predicted complications. Angiographic follow-up was available for $84 \%$ of patients at 25.4 months on average. Recanalization and retreatment rates were $39 \%$ and $33 \%$, respectively. Larger aneurysm size, increasing follow-up time, conventional coiling, and aneurysm location predicted both recurrence and retreatment. The annual rebleeding rate was $1.9 \%$. Larger aneurysm size, increasing follow-up time, and aneurysm location predicted new or recurrent hemorrhage. Favorable outcomes occurred in $92 \%$ of patients. Larger aneurysm size, poor Hunt and Hess grades, and new or recurrent hemorrhage predicted poor outcome.

CONCLUSIONS: Coiling of large and giant aneurysms has a reasonable safety profile with good clinical outcomes, but aneurysm reopening remains very common. Stent-assisted coiling has lower recurrence, retreatment, and new or recurrent hemorrhage rates with no additional morbidity compared with conventional coiling. Aneurysm size was a major determinant of recanalization, retreatment, new or recurrent hemorrhage, and poor outcome.

ABBREVIATIONS: GOS = Glasgow Outcome Score; PED = Pipeline Embolization Device

arge and giant intracranial aneurysms ( $\geq 10 \mathrm{~mm}$ ) have a poor natural history and usually warrant intervention. A recently published study from Japan reported an annual rupture rate of $4.37 \%$ for 10 - to $24-\mathrm{mm}$ aneurysms and $33.4 \%$ for aneurysms larger than $24 \mathrm{~mm}^{1}{ }^{1}$ Treatment options for large and giant aneurysms include open surgery or endovascular techniques. Surgical treatment is often challenging and can be associated with significant morbidity. ${ }^{2,3}$ Endovascular therapy has emerged as a minimally in-

Received April 29, 2013; accepted after revision May 28.

From the Department of Neurosurgery (N.C., S.T., L.F.G., A.S.D., R.M.S., C.W., S.S., L.A.M., R.R., P.J.), Thomas Jefferson University and Jefferson Hospital for Neuroscience, Philadelphia, Pennsylvania; and Department of Neurosurgery (D.H.), University of lowa, lowa City, lowa.

Please address correspondence to Pascal M. Jabbour, MD, Department of Neurosurgery, Division of Neurovascular Surgery and Endovascular Neurosurgery,

Thomas Jefferson University Hospital, 901 Walnut St, 3rd Floor, Philadelphia, PA

19107; e-mail: pascal.jabbour@jefferson.edu

http://dx.doi.org/10.3174/ajnr.A3696 vasive alternative to open surgery in most neurovascular centers. ${ }^{4,5}$ Available endovascular modalities include endosaccular coiling with or without stent/balloon assistance, endovascular parent vessel deconstruction, Onyx HD-500 (ev3, Irvine, California) embolization, and, recently, flow diversion. ${ }^{6}$ Endosaccular coiling is currently the most commonly used treatment technique for large and giant aneurysms, especially in the setting of subarachnoid hemorrhage. Parent vessel occlusion, when tolerated, is also a reliable and durable treatment typically considered in giant aneurysms. ${ }^{4}$

Despite increasing and widespread use of endovascular techniques, little is known about the morbidity rates, rehemorrhage rates, and long-term angiographic results of coiling in large and giant aneurysms. In addition, predictors of treatment outcome have not been identified. In this study, we analyzed the complications and longterm results of coiling in the largest series of large and giant aneurysms ( $\geq 10 \mathrm{~mm}$ ) to date. In addition, a multivariate logistic regression analysis was conducted to identify predictors of complications, 
recurrence, retreatment, new or recurrent hemorrhage, and clinical outcome.

\section{MATERIALS AND METHODS \\ Study Design, Participants, and Setting}

The university institutional review board approved the study protocol. We searched our prospectively maintained data base for all patients with large or giant aneurysms $(>10 \mathrm{~mm})$ who were treated with primary coil embolization in our institution between May 2004 and May 2011. A total of 324 consecutive patients with 334 aneurysms met the study criteria and constituted our study population. During the same time, 139 large or giant aneurysms were clipped at our institution; these patients were not included in the analysis. The decision to treat aneurysms with endovascular therapy was based on patient preferences, aneurysm morphology, aneurysm-parent vessel relationship, and comorbidities that rendered a patient a poor surgical candidate.

Medical charts and imaging studies were reviewed to determine patient age, sex, aneurysm size, aneurysm location, aneurysm morphology, Hunt and Hess grade, procedural specifics, procedural morbidity and mortality, immediate and follow-up angiographic results, need for retreatment, morbidity associated with recoiling, angiographic outcome of recoiling, new or recurrent hemorrhage, and clinical outcome. Treatment failure was defined as an inability to place coils into an aneurysm. Procedurerelated complications (ischemia, hemorrhage, dissections, new cranial nerve deficits) were reported regardless of their clinical significance. Thromboembolic complications were diagnosed intraoperatively on digital subtraction angiography, clinically as new deficits or change in the level of consciousness, or on CT/MR imaging (new infarcts) performed in cases of sudden neurologic compromise. Ischemic/thromboembolic complications were also recorded through follow-up. Radiographic follow-up (DSA or MR) was scheduled at 6 months, 1 year, 2 years, and 5 years after endovascular procedures. Initial aneurysm occlusion was determined as a percentage occlusion rate. Initial and follow-up angiographic images were compared to determine the rate of aneurysm recanalization. Any aneurysm that displayed a recurrence of $\geq 5 \%$ on follow-up angiography was considered recurrent. Clinical outcomes were retrospectively collected at discharge and at follow-up from follow-up notes of the attending physician and classified by using the Glasgow Outcome Score (GOS) as follows: I, deceased; II, vegetative state; III, severely disabled; IV, moderately disabled; and $\mathrm{V}$, mildly or not disabled.

\section{Aneurysm Coiling}

The decision to treat aneurysms with endovascular therapy was based on patient preferences, aneurysm morphology, aneurysmparent vessel relationship, and comorbidities that rendered a patient a poor surgical candidate. In aneurysms with a favorable geometry, the aim of treatment was selective and complete coiling of the aneurysm with preservation of the patency of the parent artery. Depending on operator preferences, wide-neck aneurysms were coiled either with stent assistance by using Neuroform (Stryker Neurovascular, Fremont, California) and Enterprise (Codman \& Shurtleff, Raynham, Massachusetts) stents or with balloon assistance by using the HyperGlide or HyperForm balloon (ev3). For unruptured aneurysms, endosaccular coiling was performed with an initial $100 \mathrm{U} / \mathrm{Kg}$ of heparin bolus and mainte- nance of activated clotting time of 2 times the patient's baseline intraoperatively. Coils (bare platinum) were placed until satisfactory aneurysm obliteration was achieved and/or placement of additional coils was not possible. Patients in whom the use of a stent was anticipated were pretreated with $81 \mathrm{mg}$ of aspirin and $75 \mathrm{mg}$ of clopidogrel 10 days before the procedure. For stent-assisted procedures performed in the setting of a subarachnoid hemorrhage, patients were loaded with $600 \mathrm{mg}$ of clopidogrel intraprocedurally and a 50-U/kg heparin bolus after deployment of the first coil. Patients were then maintained on daily doses of $75 \mathrm{mg}$ of clopidogrel and $81 \mathrm{mg}$ of aspirin for 2 months, followed by aspirin, $81 \mathrm{mg}$ daily, indefinitely. Because several operators performed the procedures, the protocols and techniques may have varied to some extent.

\section{Parent Vessel Occlusion}

Parent vessel occlusion was typically considered in giant and/or fusiform aneurysms of the internal carotid artery. Patient tolerance for permanent vessel occlusion was first assessed with a balloon test occlusion. Briefly, a balloon was advanced over a microguidewire and slowly inflated at the planned occlusion site. Complete balloon occlusion of the parent vessel was verified by proximal contrast injection. The awake patient was then monitored for 30 minutes with continuous clinical examination. The test was performed under normotensive parameters for the first 15 minutes followed by a hypotensive challenge for the remaining 15 minutes. The extent of intracranial collateral circulation was concurrently examined by angiography. The balloon test occlusion was "passed" by patients who remained neurologically intact during the test. The balloon was kept inflated, and flow arrest was confirmed angiographically. Vessel occlusion was then achieved with coils alone or with a combination of Onyx and coils. In the latter case, a few coils were initially deployed in the vessel through the inflated balloon or a separate microcatheter to create a framework for subsequent Onyx injection. Patients were closely monitored in the neurointensive care unit. All patients, including those who had experienced a subarachnoid hemorrhage, were prescribed maintenance antiplatelet therapy (usually daily aspirin).

\section{Statistical Analysis}

Data are presented as mean and range for continuous variables and as frequency for categoric variables. Analysis was carried out by using an unpaired $t$ test, $\chi^{2}$ test, Fisher exact test, and analysis of variance as appropriate. Univariate analysis was used to test covariates predictive of dependent variables: procedural complications, aneurysm recanalization, aneurysm retreatment, new or recurrent hemorrhage, and patient outcome (GOS IV-V versus I-II-III). Interaction and confounding were assessed through stratification and relevant expansion covariates. Factors predictive in univariate analysis $(P<.15)^{7}$ were entered into a multivariate logistic regression analysis. $P$ values $\leq .05$ were considered statistically significant. Statistical analysis was performed with STATA 10.0 (StataCorp, College Station, Texas).

\section{RESULTS}

A total of 324 patients with 334 large or giant aneurysms underwent coiling at our institution. Mean age was 57 years (range, 15-89 years). Seventy-seven percent of patients $(n=250)$ were 
Table 1: Location of treated aneurysms and respective complication and recurrence rates

\begin{tabular}{lcccc}
\hline \multicolumn{1}{c}{ Location } & No. of Aneurysms (\%) & Complications (\%) & Recurrence (\%) & Retreatment (\%) \\
\hline Paraclinoid & $63(18.9)$ & $9(14.3)$ & $26 / 53(49)$ & $22 / 53(41.5)$ \\
Basilar artery & $53(15.9)$ & $4(7.5)$ & $16 / 43(37.2)$ & $15 / 43(34.9)$ \\
Posterior communicating artery & $48(14.4)$ & $6(12.5)$ & $11 / 33(33.3)$ & $10 / 33(30.3)$ \\
Carotid ophthalmic & $47(14.1)$ & $3(6.4)$ & $12 / 39(30.8)$ & $10 / 39(25.6)$ \\
Anterior communicating artery & $34(10.2)$ & $5(14.7)$ & $6 / 25(24)$ & $5 / 25(20)$ \\
Carotid cavernous & $27(8.0)$ & $4(14.8)$ & $9 / 21(42.9)$ & $6 / 21(28.6)$ \\
Middle cerebral artery & $25(7.5)$ & $2(8)$ & $8 / 16(50)$ & $5 / 16(31.3)$ \\
Carotid terminus & $17(5.1)$ & $1(7.7)$ & $5 / 11(45.5)$ & $4 / 11(36.4)$ \\
Vertebral artery & $13(3.9)$ & 0 & $5 / 12(41.7)$ & $5 / 12(41.7)$ \\
Anterior cerebral artery & $6(1.8)$ & 0 & $4 / 6(66.7)$ & $4 / 6(66.7)$ \\
Posterior cerebral artery & $1(0.3)$ & 34 & $0 / 1$ & $0 / 1$ \\
Total & 334 & & 102 & 85 \\
\hline
\end{tabular}

female. Aneurysm size was $15 \mathrm{~mm}$ on average (range, 10-45 $\mathrm{mm})$. Of 334 aneurysms, $216(64 \%)$ were between 10 and $14 \mathrm{~mm}$, $86(26 \%)$ were between 15 and $24 \mathrm{~mm}$, and 32 (10\%) were $\geq 25$ $\mathrm{mm}$. Aneurysm locations are summarized in Table 1. Eighty percent of aneurysms $(n=268)$ were located in the anterior circulation (including posterior communicating artery aneurysms). Fourteen aneurysms $(4.1 \%)$ had a fusiform morphology. Hunt and Hess grades were zero in 175 (54\%) patients, I in $32(10 \%)$ patients, II in $16(4.9 \%)$ patients, III in $63(19.4 \%)$ patients, IV in $34(10.5 \%)$ patients, and V in $4(1.2 \%)$ patients.

\section{Initial Treatment}

Of 334 aneurysms, 14 (2.4\%) were initially treated with parent vessel occlusion, and 320 (97.6\%), with endosaccular coiling. Parent vessel occlusion was performed with coils alone in 5 patients and with a combination of Onyx and coils in 9 patients. Among the other 320 aneurysms, 7 (2.2\%) were treated with balloonassisted coiling; 88 (27.5\%), with stent-assisted coiling; and 225 (70.3\%), with unassisted coiling. Three patients $(0.9 \%)$ had an unsuccessful procedure and underwent surgical clipping. Seventeen patients were stent-coiled in the acute setting of subarachnoid hemorrhage.

Complications related to the initial procedure occurred in 34 $(10.5 \%)$ patients, resulting in 1 death $(0.3 \%)$. Seventeen patients died during initial hospitalization from causes unrelated to aneurysm embolization. Complications were as follows: 31 (9.6\%) thromboembolic or ischemic events (including 3 clinically silent infarcts), 2 (0.6\%) intraprocedural aneurysm ruptures, and 1 $(0.3 \%)$ cranial nerve palsy. Specifically, procedural complications occurred in $22(9.8 \%)$ patients treated with unassisted coiling, $10(11.4 \%)$ patients treated with stent-assisted coiling, and $2(14.3 \%)$ patients treated with parent vessel occlusion $(P=.7)$. The complication rate was $7.4 \%(n=13)$ for patients with unruptured aneurysms and $14 \%(n=21)$ for those with ruptured aneurysms $(P=.05)$. Complication rates were $10.2 \%$ $(n=22)$ for aneurysms between 10 and $14 \mathrm{~mm}, 10.4 \%(n=9)$ for aneurysms between 15 and $24 \mathrm{~mm}$, and $9.4 \%(n=3)$ for aneurysms of $\geq 25 \mathrm{~mm}(P=.8)$.

Table 1 summarizes complication rates per aneurysm location. Patients who were stented in the acute setting of hemorrhage did not have any hemorrhagic complications. In multivariate analysis, carotid cavernous-paraclinoid-anterior communicating artery aneurysms $(\mathrm{OR}=2.1 ; 95 \% \mathrm{CI}, 1.1-3.9 ; P=.02)$ and
Table 2: Complications and angiographic outcomes per aneurysm size

\begin{tabular}{llcc}
\hline & \multicolumn{1}{c}{$\mathbf{1 0 - 1 4} \mathbf{~ m m}$} & $\mathbf{1 5 - 2 4} \mathbf{m m}$ & $\geq 25 \mathrm{~mm}$ \\
\hline Complications & $22 / 216(10.2 \%)$ & $9 / 86(10.4 \%)$ & $3 / 32(9.4 \%)$ \\
Recurrence & $62 / 177(35 \%)$ & $29 / 62(46.8 \%)$ & $11 / 21(52 \%)$ \\
Retreatment & $52 / 177(29.3 \%)$ & $23 / 62(37.1 \%)$ & $10 / 21(47.6 \%)$ \\
\hline
\end{tabular}

ruptured aneurysms $(\mathrm{OR}=2.4 ; 95 \% \mathrm{CI}, 1.1-4.3 ; P=.04)$ were predictive of complications. There was also a trend toward anterior circulation-versus-posterior circulation aneurysms $(\mathrm{OR}=2$; 95\% CI, $0.9-5.0 ; P=.09$ ) to predict complications. The type of treatment and aneurysm size were not predictive factors.

Immediate occlusion ( $\geq 95 \%)$ was achieved in $290(87.6 \%)$ aneurysms. Excluding the 3 patients with a failed procedure and the 18 patients who died during initial hospitalization, angiographic follow-up was available for $85 \%$ of patients (260/303) at a mean of 25.4 months. Of 260 aneurysms, 102 (39\%) showed recanalization at follow-up and $85(33 \%)$ required further treatment. Initial retreatment consisted of additional coiling in 51 aneurysms, balloon-assisted coiling in 2, stent-assisted coiling in 19, Onyx HD 500 embolization in 2, Pipeline Embolization Device (PED) therapy in 2, parent vessel occlusion in 3, and microsurgical clipping in 6. Recurrence and retreatment rates (Table 2) were, respectively, $35 \%(62 / 177)$ and $29.3 \%(52 / 177)$ for aneurysms between 10 and $14 \mathrm{~mm}, 46.8 \%(29 / 62)$ and $37.1 \%$ (23/62) for aneurysms between 15 and $24 \mathrm{~mm}$, and 52\% (11/21) and 47.6\% $(10 / 21)$ for aneurysms $\geq 25 \mathrm{~mm}(P=.005, P=.003)$. Recurrence and retreatment rates were, respectively, $44 \%(72 / 164)$ and $37.2 \%$ (61/164) for unassisted coiling, 32.5\% (26/80) and 26\% (21/80) for stent-assisted coiling, 40\% (2/5) and 40\% (2/5) for balloonassisted coiling, and 18.2\% (2/11) and 9.1\% (1/11) for parent vessel occlusion $(P=.03, P=.02)$. Table 1 summarizes recanalization and recurrence rates per aneurysm location. In multivariate analysis, larger aneurysm size, increasing follow-up time, unassisted coiling and balloon-assisted coiling versus stent-assisted coiling or parent vessel occlusion, and carotid cavernous-paraclinoid-anterior cerebral artery-vertebral artery-carotid terminusmiddle cerebral artery aneurysms were independent predictors of both recurrence and retreatment (Table 3 ).

At discharge, $89 \%(n=286)$ of patients attained a favorable outcome (GOS IV-V) (Table 4). Specifically, a favorable outcome was noted in $98 \%(n=172)$ of patients with unruptured aneurysms and $77 \%(n=114)$ of patients with ruptured aneurysms. 
Table 3: Predictors of recurrence and retreatment

\begin{tabular}{|c|c|c|c|}
\hline & Odds Ratio & $95 \% \mathrm{Cl}$ & $P$ Value \\
\hline \multicolumn{4}{|l|}{ Procedural complications } \\
\hline Ruptured aneurysms & 2.4 & $1.1-4.3$ & $.04^{\mathrm{a}}$ \\
\hline Aneurysm location & 2.1 & $1.1-3.9$ & $.02^{\mathrm{a}}$ \\
\hline Anterior circulation aneurysms & 2.0 & $0.9-5.0$ & .09 \\
\hline \multicolumn{4}{|l|}{ Recurrence } \\
\hline Aneurysm size & 1.07 & $1.02-1.14$ & $.006^{\mathrm{a}}$ \\
\hline Follow-up time & 1.04 & $1.02-1.06$ & $<.001^{\mathrm{a}}$ \\
\hline Unassisted coiling and balloon remodeling & 2 & $1.1-3.3$ & $.02^{\mathrm{a}}$ \\
\hline Aneurysm location & 1.9 & $1.1-3.4$ & $.02^{\mathrm{a}}$ \\
\hline \multicolumn{4}{|l|}{ Retreatment } \\
\hline Aneurysm size & 1.08 & $1.02-1.14$ & $.003^{\mathrm{a}}$ \\
\hline Follow-up time & 1.02 & $1.02-1.06$ & $.002^{\mathrm{a}}$ \\
\hline Unassisted coiling and balloon remodeling & 2.5 & $1.1-3.3$ & $.005^{\mathrm{a}}$ \\
\hline Aneurysm location & 2.02 & $1.1-3.4$ & $.02^{\mathrm{a}}$ \\
\hline \multicolumn{4}{|l|}{ New or recurrent hemorrhage } \\
\hline Aneurysm size & 1.1 & $1.0-1.2$ & $.04^{\mathrm{a}}$ \\
\hline Follow-up time & 1.03 & $1.0-1.1$ & $.05^{\mathrm{a}}$ \\
\hline Aneurysm location & 2.5 & $1.5-7$ & $.01^{\mathrm{a}}$ \\
\hline \multicolumn{4}{|l|}{ Clinical outcome } \\
\hline Aneurysm size & 0.89 & $0.82-0.97$ & $.01^{\mathrm{a}}$ \\
\hline Hunt and Hess grades & 0.36 & $0.24-0.55$ & $<.001^{\mathrm{a}}$ \\
\hline New or recurrent hemorrhage & 0.04 & $0.005-0.28$ & $.002^{\mathrm{a}}$ \\
\hline
\end{tabular}

a Statistically significant values. Factors tested as predictors of complications: age, sex, embolization, initial aneurysm occlusion, and date of treatment. Factors tested as predictors of recurrence, retreatment, and new or recurrent hemorrhage: age, sex, aneurysm size, location, ruptured aneurysm status, Hunt and Hess grades, type of embolization, initial aneurysm occlusion, date of treatment, procedural complications, GOS at discharge, and follow-up time. Factors tested as predictors of clinical outcome: age, sex, aneurysm size, location, ruptured aneurysm status, Hunt and Hess grades, type of embolization, initial aneurysm occlusion, date of treatment, procedural complications, GOS at discharge, follow-up time, recurrence, retreatment, and new or recurrent hemorrhage.

Table 4: Clinical outcome of treated patients

\begin{tabular}{lcc}
\hline \multicolumn{1}{c}{ GOS } & Discharge (\%) & Follow-Up (\%) \\
\hline I, Death & $17(5.3)$ & $7(2.7)$ \\
II, Vegetative state & $1(0.3)$ & $1(0.4)$ \\
III, Severe disability & $18(5.6)$ & $12(4.7)$ \\
IV, Moderate disability & $21(6.5)$ & $17(6.6)$ \\
V, Mild/no disability & $265(82.3)$ & $219(85.6)$ \\
\hline
\end{tabular}

\section{Aneurysm Recoiling: Morbidity and Angiographic \\ Outcome}

Angiographic follow-up was available for 55 of the 75 aneurysms that were recoiled (including stent/balloon-assisted coiling and parent vessel occlusion). Among these 55 aneurysms, 30 (54.5\%) showed another recurrence at follow-up. Specifically, a recurrence was noted in $37.5 \%(6 / 16)$ of aneurysms retreated with stent-assisted coiling versus $61.5 \%$ (24/39) of those recoiled without stent assistance $(P=.1)$.

Of the 30 aneurysms that showed a second recurrence after coiling, 24 (43.6\%) required retreatment, including recoiling in 19 aneurysms. Angiographic follow-up was available for 15 of these 19 aneurysms, and a third recurrence was noted in 8 of these 15 aneurysms (53.3\%), requiring further treatment in 6 (40\%).

Complications were noted in 5 of the 75 patients $(6.6 \%)$ whose aneurysms required further coiling. The rate of complications per recoiling procedure was $5 \%(5 / 100)$.

\section{New or Recurrent Hemorrhage and Long-Term Clinical Outcome}

Eleven patients $(4.2 \%, n=256)$ had a new or recurrent subarachnoid hemorrhage at a median of 12 months (range, 1 week to 7 years) following successful aneurysm treatment. The annual rate of new or recurrent hemorrhage was 1.9\% (11 hemorrhages in 564 years of follow-up). Seven of these patients had aneurysm occlusion of $\geq 95 \%$ after initial embolization. Four hemorrhages occurred within 2 months of treatment. Five of these patients died, and 3 remained severely disabled at follow-up. Mean aneurysm size was $17 \mathrm{~mm}$ in this group. Ten patients had been initially treated with conventional coiling, and only 1 , with stent-assisted coiling. Thus, the rate of new or recurrent hemorrhage was $6.0 \%$ for conventional coiling versus $1.3 \%$ for stent-assisted coiling $(P=.1)$. In multivariate analysis, larger aneurysm size $(>15 \mathrm{~mm})(\mathrm{OR}=1.1 ; 95 \% \mathrm{CI}$, $1.0-1.2 ; P=.04)$, increasing follow-up time $(\mathrm{OR}=1.03 ; 95 \% \mathrm{CI}, 1.0-1.1 ; P=$ $.05)$, and basilar tip-anterior communicating-posterior communicating aneurysm locations $(\mathrm{OR}=2.5 ; 95 \% \mathrm{CI}$, $1.5-7 ; P=.01)$ were independent predictors of new or recurrent hemorrhage. The type of initial aneurysm treatment fell short of statistical significance.

Clinical follow-up was available for $85 \%$ of patients $(n=256)$ at a mean of 26.3 months, excluding patients with a failed procedure and those who died during the initial hospitalization. A favorable outcome (GOS IV-V) was attained by $92 \%(n=236)$ of patients at follow-up. Specifically, $87 \%$ (93/107) of patients with ruptured aneurysms and 96\% (143/ 149) of patients with unruptured aneurysms achieved a favorable outcome (GOS IV-V). In multivariate analysis, increasing aneurysm size $(\mathrm{OR}=0.89 ; 95 \% \mathrm{CI}, 0.82-0.97 ; P=.01)$, poor Hunt and Hess grades $(\mathrm{OR}=0.36 ; 95 \% \mathrm{CI}, 0.24-0.55 ; P<.001)$, and new or recurrent hemorrhage $(\mathrm{OR}=0.04 ; 95 \% \mathrm{CI}, 0.005-0.28$; $P=.002)$ were negative independent predictors of favorable outcome (GOS IV-V).

\section{DISCUSSION}

In this study, we have reviewed our experience with coil embolization of large and giant aneurysms $(\geq 10 \mathrm{~mm})$ and identified several independent predictors of treatment outcome. This report may serve as a reference for comparison with other treatment options for this category of aneurysm, namely flow diversion and surgical clipping. Our study has also afforded an opportunity to compare different endovascular techniques in terms of complications and angiographic outcome.

Coil embolization remains the most commonly used endovascular technique for securing large and giant aneurysms. Complications occurred in $10.5 \%$ of patients in our series, but many were clinically silent or minor events. The procedural mortality rate was minimal $(0.3 \%)$, and the rate of favorable outcome at clinical follow-up (92\%) was high. Unfortunately, to our knowledge, there are no reports in the literature pertaining specifically to large and giant aneurysms $(>10 \mathrm{~mm})$ with which to compare 
our findings. In a systematic review of giant aneurysms ( $\geq 25$ $\mathrm{mm}$ ) treated with conventional endovascular approaches, the rates of morbidity and mortality were $17 \%$ and $8 \%$, respectively. ${ }^{8}$ Gruber et $\mathrm{al}^{9}$ treated 31 very large and giant aneurysms (>20 mm) with endosaccular coiling with a $13.3 \%$ procedure-related morbidity rate and a $6.7 \%$ procedure-related mortality rate and reported favorable outcomes in $73.3 \%$ of patients. Likewise, Sluzewski et $\mathrm{al}^{10}$ achieved a good clinical outcome in nearly $80 \%$ of patients with very large and giant aneurysms $(>20 \mathrm{~mm})$ treated with coiling. The higher rate of favorable outcomes in our study likely reflects the inclusion of smaller aneurysms $(10-20 \mathrm{~mm})$ in the analysis. In fact, increasing aneurysm size was independently predictive of poor outcome, recanalization, retreatment, and new or recurrent hemorrhage in multivariate analysis. Overall, coiling of large and giant aneurysms $(\geq 10 \mathrm{~mm})$ in our experience was associated with a reasonable safety profile and good clinical outcomes. Patients with larger aneurysms, however, are at higher risk of poor outcome.

The present study demonstrates high rates of recurrence (39\%) and retreatment (33\%) for large and giant aneurysms treated with coiling. Moreover, the risk of aneurysm recurrence was $54.5 \%$ after the first recoiling and $53.3 \%$ after the second recoiling. Aneurysm reopening remains, therefore, the major shortcoming of coiling (and repeat coiling) in large and giant aneurysms. This has been attributed to thrombus resolution, coil migration into the thrombus mass, and suboptimal packing of these aneurysms. ${ }^{10}$ Our results are remarkably similar to those of Murayama et al, ${ }^{11}$ who reported, in 2003, their 11-year experience with aneurysm embolization. The recanalization rate was $35.3 \%$ for large aneurysms in their study and 59.1\% for giant aneurysms. The lack of improvement relative to this prior series published 10 years ago suggests that further improvement in occlusion/recanalization rates for large aneurysms may well require adjunctive therapy. The fact that stent-assisted coiling was associated with lower recurrence rates in multivariate analysis compared with conventional coiling (with or without balloon assistance) is a crucial finding of our study. In addition, the risk of a second aneurysm recurrence was lower when recoiling was performed withversus-without stent assistance (37.5\% versus $61.5 \%)$. Moreover, there was a lower incidence of new or recurrent hemorrhage in patients treated with stent-assisted coiling versus conventional coiling ( $1.1 \%$ versus $4.7 \%)$.

Several reasons may account for the improved durability of treatment with self-expanding stents, including denser aneurysm packing with increased neck coverage, flow diversion, parent vessel straightening, and fibroelastic tissue formation along the neck of the aneurysm. ${ }^{12-16}$ Most important, the lower recurrence and rebleeding rates with stent-assisted techniques did not occur at the expense of an increased rate of complications. Previously, Piotin et $\mathrm{al}^{17}$ reported permanent neurologic deficit and mortality rates as high as $7.4 \%$ and $4.6 \%$, respectively, with stent-assisted coiling compared with $3.8 \%$ and $1.2 \%$ with conventional coiling. Our study emphasizes the safety and efficacy of stent-assisted coiling and suggests that it may be the preferred treatment technique over conventional coiling for large and giant aneurysms.

The annual rebleeding rate was $1.9 \%$ in our study, exceeding the rate reported in the endovascular arm of the International
Subarachnoid Aneurysm Trial. ${ }^{18}$ This is expected given that $92 \%$ of coiled aneurysms in this trial were $\leq 10 \mathrm{~mm}$. Rebleeding occurred both early and late after initial coiling and was independently predictive of poor clinical outcome. Larger aneurysms $(>15 \mathrm{~mm})$ and basilar tip, anterior communicating, and posterior communicating aneurysms were strong predictors of rebleeding. Thus, patients with these risk factors should be very carefully followed and retreated, preferentially with stent-assisted techniques, in the event of aneurysm reopening to prevent rehemorrhage.

Recoiling in the present study was associated with a relatively low complication rate (5\%) and no mortality. Previous studies have reported similarly low morbidity rates with recoiling. A multicenter study of 100 aneurysms requiring additional coiling because of an enlarging remnant and subtotal occlusion reported minor permanent neurologic deficits in only $3 \%$ of cases. ${ }^{19}$ Likewise, Kang et $\mathrm{al}^{20}$ and Slob et $\mathrm{al}^{21}$ observed no complications during repeat embolization of recurrent aneurysms and suggested that procedural morbidity for retreatment may be lower than that for initial coiling.

The rate of complications for unruptured large and giant aneurysms in our study was low (7.4\%), and excellent outcomes were achieved in this group. The best endovascular technique for these aneurysms (ie, coiling versus flow diversion), however, is not clear. In a small series of 42 patients, Lanzino et $\mathrm{al}^{22}$ reported similar rates of morbidity and a higher rate of complete angiographic obliteration with the PED (mean aneurysm size, 14.9 $\mathrm{mm}$ ) compared with standard endovascular techniques (mean aneurysm size, $13.9 \mathrm{~mm}$ ). The authors concluded that careful long-term follow-up was important to definitively validate flow diversion as a superior treatment for proximal internal carotid artery aneurysms. Elsewhere, flow diversion was associated with significant procedural risks. A recent systematic review on unruptured aneurysms treated with endovascular techniques found that flow diversion was associated with significantly higher risks compared with other endovascular techniques. ${ }^{23}$ The risk of major stroke or neurologic death was 5.6\% in the Pipeline for Uncoilable or Failed Aneurysms trial ${ }^{24}$ (mean aneurysm size, $14.6 \mathrm{~mm}$ ) and $8.5 \%$ (including 4 fatal postprocedural hemorrhages) in a recent multicenter study from 7 American neurosurgical centers (proportion of aneurysms larger than $7 \mathrm{~mm}, 83 \%) .{ }^{25}$ In the Canadian experience (mean aneurysm size, $19 \mathrm{~mm}$ ), the overall morbidity and mortality rate associated with PED treatment was $10.7 \%$ (6.3\% mortality, $4.4 \%$ morbidity). ${ }^{26}$

These data suggest that the risk associated with flow diversion is not insignificant and that further study is needed to elucidate the best treatment option for unruptured large and giant aneurysms. On the other hand, for patients with acutely ruptured aneurysms, flow diversion is barely an option and almost all aneurysms are either coiled or clipped. McAuliffe and Wenderoth ${ }^{27}$ treated 11 patients with recently ruptured aneurysms by using the PED and reported 2 deaths during the acute illness due to aneurysm rebleeding (18\%). The authors recommended that the device be used as a coil scaffold rather than a flow diverter. In the posterior circulation as well, flow diversion is generally used very cautiously because it is associated with significant morbidity and high rates of perforator infarcts. ${ }^{25,28,29}$ Conversely, in the present 
study, there was a trend toward lower complication rates with coiling in the posterior circulation. Thus, coiling remains the preferred option for ruptured aneurysms and posterior circulation aneurysms.

Parent vessel occlusion is widely used in the management of giant intracranial aneurysms. The complication rate in the present series $(14.3 \%)$ was within the range reported in the literature, ${ }^{16,30-33}$ and aneurysm reopening was somewhat uncommon. The advantage of the technique is that it excludes the aneurysm definitely from the circulation and may not require follow-up imaging. ${ }^{4}$ In contrast to flow diverters and endosaccular coiling, there is practically no risk of delayed aneurysm rupture after parent vessel occlusion. For some authors, parent vessel occlusion is the safest and most effective treatment for large and giant aneurysms and remains the first-line option in this setting. ${ }^{34}$ The main disadvantage of parent vessel occlusion is the risk of development of postoperative stroke. Therefore, it is important to perform a balloon test occlusion to determine patient tolerance for permanent arterial occlusion because the incidence of postoperative stroke is substantially higher without previous tolerance testing. ${ }^{35-37}$ Also, in the setting of subarachnoid hemorrhage, parent vessel occlusion is generally avoided due to potential aggravation of ischemic complications of vasospasm.

This was a retrospective review of a single-center experience with coiling of large and giant aneurysms. There was no randomization of the different subgroups of the study. Comparison with other studies reporting on flow diversion or surgical clipping remains limited by inherent differences in methodology and design. In the future, it would be interesting to compare conventional endovascular techniques with flow diversion or surgical clipping to determine the best technique in this setting.

\section{CONCLUSIONS}

In this study, coiling of large and giant aneurysms was associated with a reasonable safety profile and good clinical outcome. Aneurysm reopening, however, was very common after endosaccular coiling. Larger aneurysm size was independently predictive of recanalization, retreatment, new or recurrent hemorrhage, and poor outcome. Stent-assisted coiling was associated with lower recurrence, retreatment, and new or recurrent hemorrhage rates with no additional morbidity compared with conventional coiling. Thus, stent-assisted coiling should probably be considered the preferred treatment option over conventional coiling for large and giant aneurysms. The annual rebleeding rate was $1.9 \%$, and larger aneurysms $(>15 \mathrm{~mm})$ and basilar tip, anterior communicating artery, and posterior communicating artery aneurysms were strong predictive factors. The major determinants of clinical outcome were aneurysm size, Hunt and Hess grades, and new or recurrent hemorrhage.

Disclosures: Stavropoula Tjoumakaris-UNRELATED: Consultancy: Stryker. Aaron S. Dumont-UNRELATED: Consultancy: ev3. Pascal Jabbour-UNRELATED: Consultancy: ev3, CNV.

\section{REFERENCES}

1. Morita A, Kirino T, Hashi K, et al. The natural course of unruptured cerebral aneurysms in a Japanese cohort. $N$ Engl $\mathrm{J}$ Med 2012;366:2474-82
2. Sundt TM Jr, Piepgras DG. Surgical approach to giant intracranial aneurysms: operative experience with $\mathbf{8 0}$ cases. J Neurosurg 1979;51:731-42

3. Kalani MY, Zabramski JM, Hu YC, et al. Extracranial-intracranial bypass and vessel occlusion for the treatment of unclippable giant middle cerebral artery aneurysms. Neurosurgery 2013;72:428-35, discussion 435-36

4. van Rooij WJ, Sluzewski M. Endovascular treatment of large and giant aneurysms. AJNR Am J Neuroradiol 2009;30:12-18

5. Roy D, Milot G, Raymond J. Endovascular treatment of unruptured aneurysms. Stroke 2001;32:1998-2004

6. Chalouhi N, Jabbour P, Singhal S, et al. Stent-assisted coiling of intracranial aneurysms: predictors of complications, recanalization, and outcome in $\mathbf{5 0 8}$ cases. Stroke 2013;44:1348-53

7. Altman DG. Practical Statistics for Medical Research. Boca Raton, Florida: Chapman \& Hall/CRC; 1999

8. Parkinson RJ, Eddleman CS, Batjer HH, et al. Giant intracranial aneurysms: endovascular challenges. Neurosurgery 2008;62(6 suppl 3):1336-45

9. Gruber A, Killer M, Bavinzski G, et al. Clinical and angiographic results of endosaccular coiling treatment of giant and very large intracranial aneurysms: a 7-year, single-center experience. Neurosurgery 1999;45:793-803, discussion 803-04

10. Sluzewski M, Menovsky T, van Rooij WJ, et al. Coiling of very large or giant cerebral aneurysms: long-term clinical and serial angiographic results. AJNR Am J Neuroradiol 2003;24:257-62

11. Murayama Y, Nien YL, Duckwiler G, et al. Guglielmi detachable coil embolization of cerebral aneurysms: 11 years' experience. J Neurosurg 2003;98:959-66

12. Chalouhi N, Dumont AS, Hasan D, et al. Is packing density important in stent-assisted coiling? Neurosurgery 2012;71:381-86, discussion 386-87

13. Chalouhi N, Drueding R, Starke RM, et al. In-stent stenosis after stent-assisted coiling: incidence, predictors and clinical outcomes of 435 cases. Neurosurgery 2013;72:390-96

14. Chalouhi N, Jabbour P, Gonzalez LF, et al. Safety and efficacy of endovascular treatment of basilar tip aneurysms by coiling with and without stent assistance: a review of 235 cases. Neurosurgery 2012;71:785-94

15. Jahshan S, Abla AA, Natarajan SK, et al. Results of stent-assisted vs non-stent-assisted endovascular therapies in 489 cerebral aneurysms: single-center experience. Neurosurgery 2013;72:232-39

16. Chalouhi N, Starke RM, Koltz MT, et al. Stent-assisted coiling versus balloon remodeling of wide-neck aneurysms: comparison of angiographic outcomes. AJNR Am J Neuroradiol 2013;34:1987-92

17. Piotin M, Blanc R, Spelle L, et al. Stent-assisted coiling of intracranial aneurysms: clinical and angiographic results in 216 consecutive aneurysms. Stroke 2010;41:110-15

18. Molyneux AJ, Kerr RS, Birks J, et al. Risk of recurrent subarachnoid haemorrhage, death, or dependence and standardised mortality ratios after clipping or coiling of an intracranial aneurysm in the International Subarachnoid Aneurysm Trial (ISAT): long-term follow-up. Lancet Neurol 2009;8:427-33

19. Renowden SA, Koumellis P, Benes V, et al. Retreatment of previously embolized cerebral aneurysms: the risk of further coil embolization does not negate the advantage of the initial embolization. AJNR Am J Neuroradiol 2008;29:1401-04

20. Kang HS, Han MH, Kwon BJ, et al. Repeat endovascular treatment in post-embolization recurrent intracranial aneurysms. Neurosurgery 2006;58:60-70, discussion 60-70

21. Slob MJ, Sluzewski M, van Rooij WJ, et al. Additional coiling of previously coiled cerebral aneurysms: clinical and angiographic results. AJNR Am J Neuroradiol 2004;25:1373-76

22. Lanzino G, Crobeddu E, Cloft HJ, et al. Efficacy and safety of flow diversion for paraclinoid aneurysms: a matched-pair analysis compared with standard endovascular approaches. AJNR Am J Neuroradiol 2012;33:2158-61

23. Naggara ON, Lecler A, Oppenheim C, et al. Endovascular treatment 
of intracranial unruptured aneurysms: a systematic review of the literature on safety with emphasis on subgroup analyses. Radiology 2012;263:828-35

24. Becske T, Kallmes DF, Saatci I, et al. Pipeline for uncoilable or failed aneurysms: results from a multicenter clinical trial. Radiology 2013;267:858-68

25. Kan P, Siddiqui AH, Veznedaroglu E, et al. Early postmarket results after treatment of intracranial aneurysms with the Pipeline embolization device: a U.S. multicenter experience. Neurosurgery 2012;71: 1080-88, discussion 1087-88

26. O'Kelly CJ, Spears J, Chow M, et al. Canadian experience with the Pipeline embolization device for repair of unruptured intracranial aneurysms. AJNR Am J Neuroradiol 2013;34:381-87

27. McAuliffe W, Wenderoth JD. Immediate and midterm results following treatment of recently ruptured intracranial aneurysms with the Pipeline embolization device. AJNR Am J Neuroradiol 2012;33:487-93

28. Phillips TJ, Wenderoth JD, Phatouros CC, et al. Safety of the Pipeline embolization device in treatment of posterior circulation aneurysms. AJNR Am J Neuroradiol 2012;33:1225-31

29. Chalouhi N, Tjoumakaris S, Dumont AS, et al. Treatment of posterior circulation aneurysms with the Pipeline embolization device. Neurosurgery 2013;72:883-89

30. Barr JD, Lemley TJ. Endovascular arterial occlusion accomplished using microcoils deployed with and without proximal flow arrest: results in 19 patients. AJNR Am J Neuroradiol 1999;20:1452-56

31. Graves VB, Perl J 2nd, Strother CM, et al. Endovascular occlusion of the carotid or vertebral artery with temporary proximal flow arrest and microcoils: clinical results. AJNR Am J Neuroradiol 1997;18:1201-06

32. Larson JJ, Tew JM Jr, Tomsick TA, et al. Treatment of aneurysms of the internal carotid artery by intravascular balloon occlusion: longterm follow-up of 58 patients. Neurosurgery 1995;36:26-30, discussion 30

33. Lewis AI, Tomsick TA, Tew JM Jr. Management of $\mathbf{1 0 0}$ consecutive direct carotid-cavernous fistulas: results of treatment with detachable balloons. Neurosurgery 1995;36:239-44, discussion 244-45

34. van Rooij WJ, Sluzewski M, van der Laak C. Flow diverters for unruptured internal carotid artery aneurysms: dangerous and not yet an alternative for conventional endovascular techniques. AJNR Am J Neuroradiol 2013;34:3-4

35. Serbinenko FA. Balloon catheterization and occlusion of major cerebral vessels. J Neurosurg 1974;41:125-45

36. American Society of Interventional and Therapeutic Neuroradiology. Carotid artery balloon test occlusion. AJNR Am J Neuroradiol 2001; 22(8 suppl):S8-9

37. Sorteberg A, Bakke SJ, Boysen M, et al. Angiographic balloon test occlusion and therapeutic sacrifice of major arteries to the brain. Neurosurgery 2008;63:651-60, discussion 660-61 